\title{
The Effect of Atmospheric Oxygen on the Emission of Volatile Organic Compounds from Contaminated Sites
}

\author{
Arthur N. Nwachukwu ${ }^{1,2}$, Bassey E. Ephraim ${ }^{3}$, Nkechinyere V. Nwachukwu ${ }^{4}$, Clementina U. Uwah ${ }^{5}$ \\ ${ }^{1}$ Williamson Research Centre for Molecular Environmental Sciences School of Earth, Atmospheric and Environmental \\ Sciences, The University of Manchester, UK, M13 9PL. \\ ${ }^{2}$ Department of Physics, Alex Ekwueme Federal University, Ndufu-Alike Ikwo, Ebonyi State, Nigeria \\ ${ }^{3}$ Department of Geology, University of Calabar, Calabar, Cross River State, Nigeria \\ ${ }^{4}$ Department of Community Medicine, Alex Ekwueme Federal University Teaching Hospital, Abakaliki, Ebonyi State, \\ Nigeria \\ ${ }^{5}$ Department of Biology, Alex Ekwueme Federal University, Ndufu-Alike Ikwo, Ebonyi State, Nigeria
}

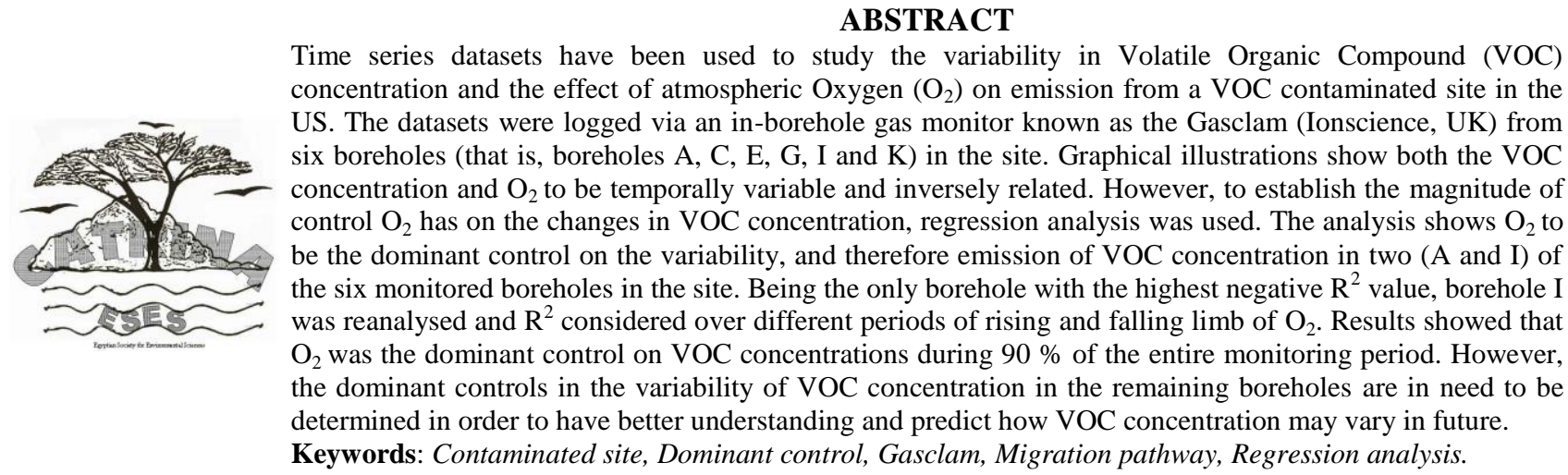

\section{INTRODUCTION}

VOCs are combustible and can trigger fire (HSE, 2000), and the availability of large amount of VOCs in the environment may constitute risk to human health because of their likelihood to cause cancer (IARC, 2004; Rowe et al., 2007). VOCs can adversely affect the body organs (like liver, kidneys, spleen, and stomach) and body systems (like nervous, circulatory, reproductive, immune, cardiovascular and respiratory systems) (Wolkoff et al., 2006; Mendel, 2007; Rowe et al., 2007; Mazzone, 2008; Mazzatenta et al., 2013; USEPA, 2014; Mazzatenta et al., 2014, Mazzatenta et al., 2015a, b; EPA, 2017; Minnesota Department of Health 2018; Invitto and Mazzatenta, 2019). Hence, there is a growing worry about its movement from the underground into overlying structures like buildings (Lynge et al., 1997; Srivastava et al., 2005; Maximilian and Ryan, 2009; Sergio et al., 2012; Nwachukwu and Henry, 2016). Although, monitoring VOC concentrations is usually encouraged; this may not be enough remediation measures, as there is also the need to adequately understand how they will change in future. To do this successfully, knowledge of the controls on the variability in VOC concentration is required.

For VOCs in soil gas, the main migration mechanism is typically diffusion (Environmental Agency, 2008). Therefore, the deeper the source is within the subsurface, the shallower the diffusive concentration gradient. Other known environmental controls which are responsible for the migration and variability of ground-gases in soil gas through the unsaturated zone include variations in atmospheric pressure, groundwater depth, production rate, soil permeability and anthropogenic sources(Choi and Smith, 2005;Tillman and Weaver, 2005).

Variability in barometric pressure is known to control the movement of ground-gases in the subsurface; however, it is likely to have more control on the migration near the surface or in specific site settings (Katy et al., 2009; Nwachukwu and Anonye, 2013). When barometric pressure decreases, the soil gas volume increases resulting in vertical migration of the gases. Contrarily, when barometric pressure rises, the soil gas concentration is diluted as air flows into the ground. Therefore, establishing variability in barometric pressure is vital in determining controls on gas concentration and migration (Tillman and Smith, 2005; Katy et al., 2009; Boult et al., 2011).

Groundwater also plays important role in the variability and migration of ground-gas. When groundwater rises, the amount of gas within the pore spaces will drop, causing gas pressure to increase and leading to lateral migration referred to as the "piston effect" (Davis et al., 2004). Heavy rainfall may also increase soil moisture content, causing momentary sealing of the earth surface, especially in fine grained soil. This reduces the potential for vertical migration of VOCs in soil gas, sometimes promoting transient lateral migration (Katy et al., 2009).

For VOC in ground-gas to move away from its origin, there should be a migration mechanism and an available pathway (Katy et al., 2009). For migration to be sustained, a continuing source of VOCs is also needed. If ground-gas production is fast enough, it can be a driving force of migration. Typically away from the source, this is not the case as the movement of the fluids (atmospheric pressure and groundwater) drives migration. This change in production can either raise or 
reduce the concentration of the soil gas causing variability in their concentrations (Katy et al., 2009).

The soil permeability is a link between soil gas and other environmental controls (Nwachukwu and Anonye, 2013). The relationships of gas concentration and its controls may vary due to the lag caused by variation in the soil permeability and gas production rate. Permeability depends on the ground cover and also might change with depth. Variability in permea-bility is a function of several factors like saturation, freezing, bioturbation and compaction (Wilson et al., 2007).

This work seeks to establish if Atmospheric Oxygen $\left(\mathrm{O}_{2}\right)$ constitutes a control on the variability in VOC concentration, and to determine the magnitude of such control. To do this successfully, it will be necessary to measure both VOC concentration and $\mathrm{O}_{2}$ at high temporal resolution, in order to detect variability in them. Their variability will then give a picture of how one change is relative to the other.

\section{MATERIALS AND METHODS}

The datasets evaluated in this study, at a site in the United States, were collected by means of an inborehole gas monitor, Gasclam (Nwachukwu et al., 2018; Nwachukwu and Uwa, 2018). The Gasclam is designed to continuously monitor different groundgases $\left(\mathrm{CH}_{4}, \mathrm{CO}_{2}, \mathrm{CO}, \mathrm{O}_{2}, \mathrm{H}_{2} \mathrm{~S}\right.$, and VOCs) and their environmental controls (temperature, barometric pressure, borehole pressure and soil water depth) altogether on hourly sampling interval, unmanned for about three months. It collects long term, genuine trend information, allowing informed conclusion to be made on accurate, dependable data - a novelty in gas management and prediction. It measures the gases with the aid of the sensors incorporated into it. Its sampling rate can be set and is variable from two minutes, to once daily. Data can be downloaded to a PC or viewed remotely using the optional GPRS telemetry system (Nwachukwu 2015a, b, c; Nwachukwu and Henry, 2017).

Gasclam units containing a continuous Photoionization detectors (PIDs) were installed in 6 boreholes (which are A, C, E, G, I and K respectively) at a site contaminated by VOCs in USA. The intention was to monitor VOC concentrations and their controls, continuously on hourly sampling intervals for different periods. The continuous data from the PID were downloaded and analysed to determine whether VOC emission and their concentrations are dependent on variability of Atmospheric Oxygen $\left(\mathrm{O}_{2}\right)$. The linear relationship resulted will summarise the magnitude of the influence of one or more independent variables on a dependent variable (Ayyub and McCuen, 2011). In the case of two variables (as in ours), one of the variable is assigned an independent variable $\left(\mathrm{O}_{2}\right)$, and the other is a dependent variable (VOC concentration). The investigated period was taken from October 2010 to August 2011 at the selected site in USA. The datasets were classified on monthly basis to determine the effect of seasonal changes on the relationships of VOC concentration and $\mathrm{O}_{2}$, where the soil during winter and beginning of spring becomes impermeable as the pore spaces are covered by snow, thereby sealing the soil from atmospheric interactions.

\section{RESULTS}

The datasets collected in the studied site, at different time intervals of the investigation period (October 2010 to August 2011), are represented in Figures 1 and 2. The datasets showed variability in VOC concentrations as a function of $\mathrm{O}_{2}$ concentrations. Whenever $\mathrm{O}_{2}$ seemed not to have control on the variability of VOC

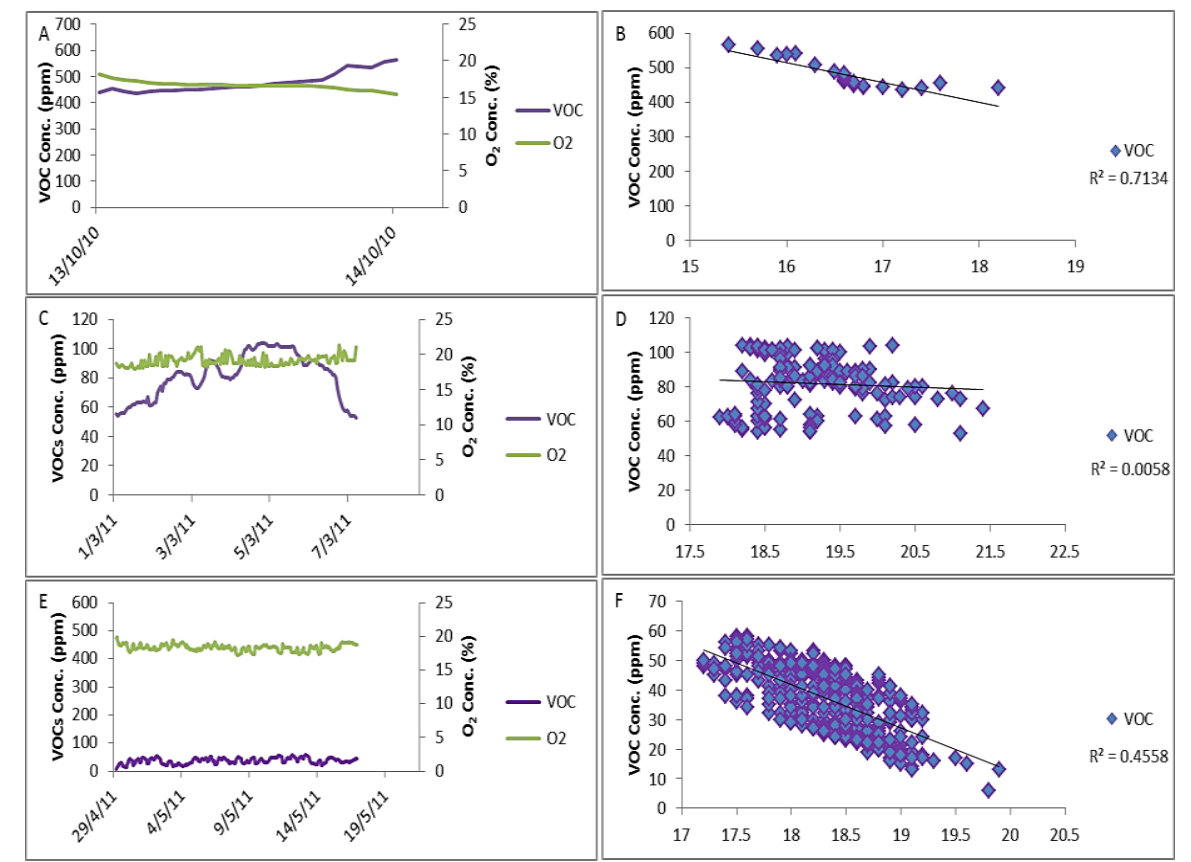

Figure (1): The measured VOC concentration values in relation to $\mathrm{O}_{2}$. A, C, E represent relationships of VOC and atmospheric oxygen in boreholes $\mathrm{A}, \mathrm{C}$ and $\mathrm{E}$, respectively; $\mathrm{B}, \mathrm{D}$ and $\mathrm{F}$ represent their respective correlations $\left(\mathrm{R}^{2}\right)$ over the time period of October 2010, March 2011 and May 2011 respectively. 


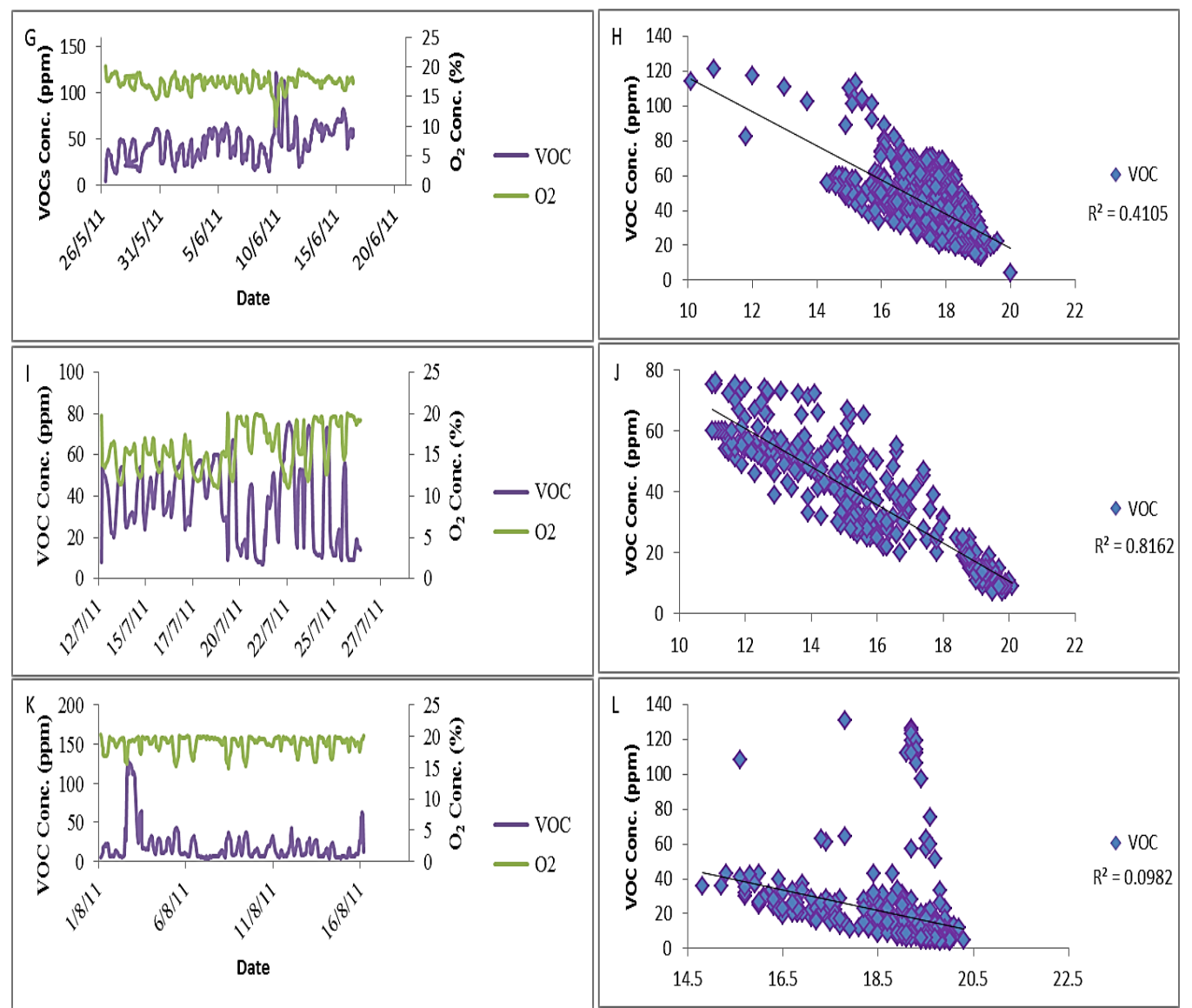

Figure (2): The measured VOC concentration values in relation to $\mathrm{O}_{2}$. G, I, K represent relationships of VOC and atmospheric oxygen in boreholes G, I and K; H, J and L represent their respective correlations $\left(\mathrm{R}^{2}\right)$ over the time period of May to August (2011) for the same site.

concentration, the possible reasons may be due to changes in season and soil permeability. The effect of hysteresis in dissociation was also suggested. As shown (Figure 1-2), A, C, E, G, I, and K represent variation in VOC concentrations against $\mathrm{O}_{2}$ concentrations; while $\mathrm{B}, \mathrm{D}, \mathrm{F}, \mathrm{H}, \mathrm{J}$ and $\mathrm{L}$ represent their respective $R^{2}$ values. These $R^{2}$ values determine the magnitude of control $\mathrm{O}_{2}$ has on the variability of VOC concentration. Because borehole I displayed the highest negative $\mathrm{R}^{2}$ value, it was thought it wise to subject it to reanalysis, to further improve on the correlation of $\mathrm{O}_{2}$ and VOC concentration (Figure $3 \mathrm{~A}$ ), and also to determine the effect of hysteresis (Figure 3b) over separate periods of rising and falling $\mathrm{O}_{2}$ concentration during the entire monitoring period. Hysteresis is the delay of VOC concentration to change over changes in Atmospheric Oxygen. This delay could be due to ground cover (soil permeability) and gas availability. While ground cover blocks the VOC in the soil gas from interacting with Atmospheric Oxygen, gas availability which is a function of ground-gas production rate determines if there is enough gas that can be forced out of the soil by $\mathrm{O}_{2}$. The $\mathrm{R}^{2}$ values during the reanalysis periods are displayed in table 1 .
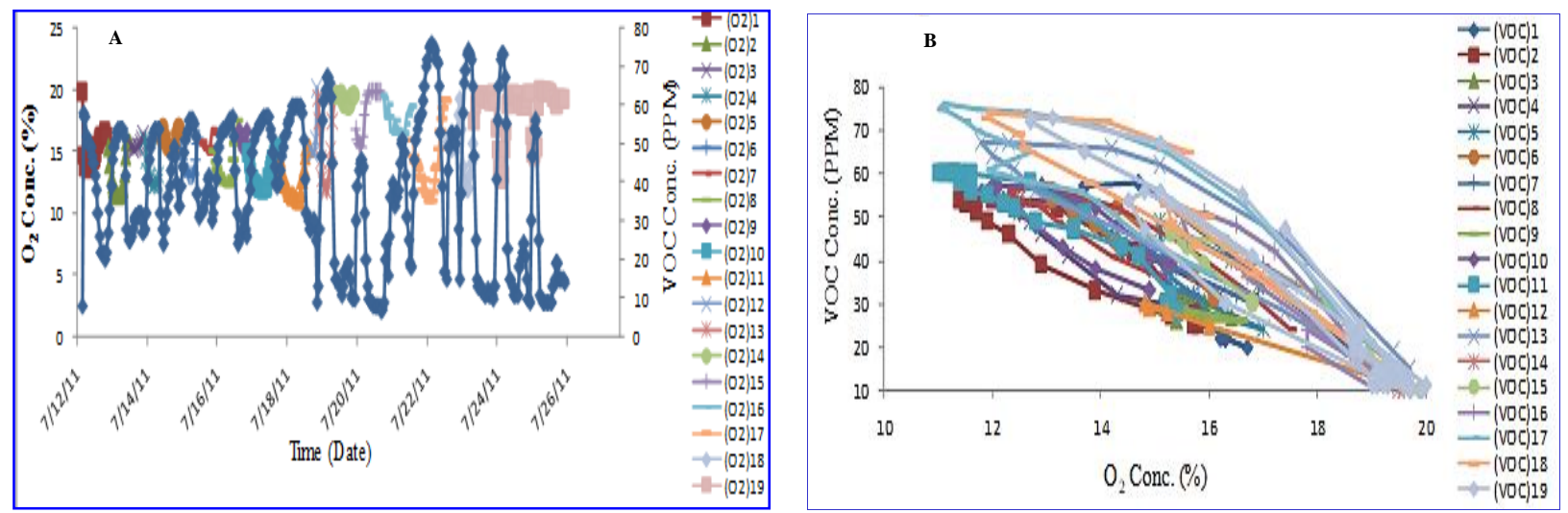

Figure (3): The VOC measured concentrations in relation to different Atmospheric Oxygen $\left(\mathrm{O}_{2}\right)$ concentrations. A, the measured VOC concentration (ppm) in relation to given $\mathrm{O}_{2}$ concentration (in percent) as a function of time. The data series is split into sections 1-19. Series split is based on the periods of $\mathrm{O}_{2}$ changing; $\mathrm{B}$. analysis is for the entire dataset; different sections of VOC concentration changes with Atmospheric Oxygen are indicated by different colours. 
Regression analysis calculated showed that the negative $\mathrm{R}^{2}$ value, between VOC concentration and Atmospheric Oxygen, were more than 0.5 except for $\mathrm{O}_{2}$ level (section 3, Table 1). Therefore, one can say that Atmospheric Oxygen is considered the dominant control during the monitoring period. Moreover, in table 1 , the $\mathrm{R}^{2}$ recorded the highest values, during the 19 sub-periods of the entire monitoring period, in section 12 followed by $15,19,6$ and $11 . \mathrm{R}^{2}$ values revealed that $\mathrm{O}_{2}$ was the dominant control on the variability and emission of VOC concentration during $17 / 19$ of the sub-periods, which represents approx.imately $90 \%$ of the entire monitoring period.

Table (1): Value of regression analysis $\left(\mathrm{R}^{2}\right)$, between VOC emission and $\mathrm{O}_{2}$ levels (sections), represents the significance correlation between the selected parameters.

\begin{tabular}{cc}
\hline \hline $\begin{array}{c}\mathbf{O}_{2} \text { Levels } \\
\text { (Sections) }\end{array}$ & $\mathbf{R}^{2}$ Values \\
\hline 1 & 0.838 \\
2 & 0.874 \\
3 & 0.101 \\
4 & 0.845 \\
5 & 0.471 \\
6 & 0.941 \\
7 & 0.667 \\
8 & 0.889 \\
9 & 0.815 \\
10 & 0.730 \\
11 & 0.914 \\
12 & 0.999 \\
13 & 0.865 \\
14 & 0.736 \\
15 & 0.964 \\
16 & 0.899 \\
17 & 0.835 \\
18 & 0.867 \\
19 & 0.946 \\
\hline \hline
\end{tabular}

\section{DISCUSSION}

A cursory appraisal of the datasets presented in Figures 1 and 2 show that $\mathrm{VOC}$ and $\mathrm{O}_{2}$ exhibit a clearly defined inverse relationship $(\mathrm{B}, \mathrm{D}, \mathrm{F}, \mathrm{H}, \mathrm{J}, \mathrm{L})$, which imply both negative correlation and an $\mathrm{O}_{2}$ control (Boult et al., 2011). This inverse relationship is very strong in boreholes $\mathrm{A}$ and $\mathrm{I}$; moderate in borehole $\mathrm{G}$ and $\mathrm{E}$; and very weak in borehole $\mathrm{C}$ and K. In Figure $1 \mathrm{~A}$, the dataset collected over a period of two days in October 2010 yielded good inverse relationship between VOC and $\mathrm{O}_{2}$, despite the low range and $\mathrm{VOC} / \mathrm{O}_{2}$ variability. The magnitude of this inverse relationship is quite high as shown in Figure 1B. Indication is that atmospheric oxygen constituted a major control on the variability in VOC concentration during this short period. This result validates the findings of Seewald et al. (2010) and Stotzky and Schenck (1976) that under decreased $\mathrm{O}_{2}$ concentration (anaerobic conditions), the diversity and amount of VOCs emitted is increased while the reverse is the case under increased $\mathrm{O}_{2}$ concentration (aerobic conditions).
In Figure $1 \mathrm{C}$, the measured $\mathrm{VOC}$ and $\mathrm{O}_{2}$ concentrations displayed higher variability in the month of March 2011, compared to what obtained in October 2010 (Figure 1A). The $\mathrm{O}_{2}$ concentration is more variable than VOC contents, and because of the differences in the degree of $\mathrm{VOC} / \mathrm{O}_{2}$ variability, the displayed inverse relationship is weak, as shown by the very low negative $\mathrm{R}^{2}$ value of 0.0058 (Figure 1D) presented. This very weak relationship may have been due to reduced permeability of the soil during the monitoring period (beginning of spring) which cut-off the VOC in the soil gas from interacting with Atmospheric $\mathrm{O}_{2}$. In parallel study done by Nwachukwu and Anonye (2013), they recorded the same observation in which decrease in soil permeability reduced the level of control of atmospheric pressure on $\mathrm{CH}_{4}$ and $\mathrm{CO}_{2}$ concentration during the monitoring periods of the study.

The variability in the concentrations of VOC and $\mathrm{O}_{2}$ is much higher in May 2011 than in the previous periods (Figure 1E). This is associated with a better inverse relationship, than what obtained in March (Figure 1F). This can be explained by low soil permeability where at the beginning of spring the soil pore spaces were covered by snow. This data is in confirmation with data obtained by Mari et al., (2018). In their study they explained the low emission of VOC and in sequence low concentration may be due to the shrink in air space between soil particles.

The range and variability of both VOC and $\mathrm{O}_{2}$ concentration during the study period of late May to June 2011 were relatively high (Figure 2G), where VOC and $\mathrm{O}_{2}$ concentrations showed a better inverse relationship. However, in the rest of the monitoring periods, this is not perfect. This is validated by the negative $\mathrm{R}^{2}$ value that they displayed (Figure $2 \mathrm{H}$ ). This fluctuation may be enlightened by the idea that the atmospheric oxygen was not always the dominant control. This agrees with the data obtained by Nwachukwu and Nwachukwu (2020) who showed that relationships of ground-gas and environmental parameters improved with improvement in the soil permeability. Meanwhile, the range and variability of VOC concentration, as a function of $\mathrm{O}_{2}$ concentration, recorded high values during the monitoring period of July (Figure 2I) where an improvement in the inverse relationship is observed. This is certified by the high negative $\mathrm{R}^{2}$ value (Figure $2 \mathrm{~J}$ ). In parallel, the data recorded in October 2010 displayed that the atmospheric oxygen could be the major control on the variability in VOC concentration. This result further validates the findings of Nwachukwu and Anonye (2013). As in July, the range and variability of VOC concentration for dataset collected in August 2011 (Figure 2K) is high. However, several periods of rising and falling in VOC concentration does not correspond with the fall and rise in atmospheric oxygen concentration, thereby producing a very weak negative relationship as indicated by the recorded $\mathrm{R}^{2}$ value, (Figure 2L). Over again, as in some earlier mentioned cases, the soil permeability may be the reason for the 
observed weak relationship of VOC concentration and Atmospheric $\mathrm{O}_{2}$ during this monitoring period (end of summer).

In order to determine the extent of control $\mathrm{O}_{2}$ has on VOC concentrations during periods of rising and falling limbs of VOC concentrations, a dataset represented by Figure 2I was used. It was chosen because, it was during this period that $\mathrm{O}_{2}$ and VOC concentrations had the highest negative correlation. The dataset was re-analysed, and presented as Figure $3 \mathrm{a}$ with various colours depicting different periods of rising and falling $\mathrm{O}_{2}$ concentrations. The clear loops created by connection of data-points in time order imply that gas concentration is affected by hysteresis (Figure $3 a$ ). The loops are more apparent in the relations of $\mathrm{O}_{2}$ versus VOC concentrations (Figure $3 \mathrm{~b}$ ). Numerous periods of falling and rising Atmospheric Oxygen reveal strong negative $\mathrm{R}^{2}$ with VOC concentrations (Table 1 ). These negative correlations support the guidance requirement for measurement sequel to falling environmental control (Katy et al., 2009, Boult et al., 2011) in order to raise the confidence in detecting the worst case. The $\mathrm{R}^{2}$ was slightly improved by considering their concentrations over individual periods of rising and falling $\mathrm{O}_{2}$ concentrations as denoted by sections 1 - 19 (Figure $3 \mathrm{a}$, Table 1); the $\mathrm{R}^{2}$ increased significantly at the $95 \%$ confidence level. This further confirmed that Atmospheric Oxygen was a major control on the behaviour of VOC concentrations during the monitoring period. There was no need considering separate periods of rising and separate periods of falling of $\mathrm{O}_{2}$ concentration, since the correlation had been improved significantly.

\section{CONCLUSION}

While information about variability in oxygen concentrations is available, no environmental parameter data were collected during this time. There is variability in the relationship between VOCs and Atmospheric Oxygen as considered in the light of continuous monitoring periods of increasing length in this site. However, it was only in two of the six boreholes that the control on VOC concentration was dominated by Atmospheric Oxygen. This behaviour of Atmospheric Oxygen in the two boreholes is similar to the established relationship of barometric pressure and ground-gas. Under conditions of falling Atmospheric Oxygen, increased vertical migration of VOC concentration occurred as the soil gas increases in volume. Conversely, rising Atmospheric Oxygen causes air to flow into the ground diluting soil gas concentrations. Although they are inversely related in the two boreholes, the monitoring periods are too short, thus making it difficult to determine how VOCs concentration will behave in future. Therefore, the monitoring period should be increased in subsequent site visit. Since the relationship between VOCs and Atmospheric Oxygen is an inverse one in the two boreholes, Atmospheric Oxygen could have been the only reason for observed changes in VOCs concentration during those monitoring periods, and therefore may be the dominant control.
Change in season may be the reason for the observed 'almost zero' relationships of VOCs concentration and Atmospheric $\mathrm{O}_{2}$ in boreholes $\mathrm{C}$ and $\mathrm{K}$ as the soil might have been sealed from the atmosphere during the two periods. As Atmospheric Oxygen is not the dominant control in majority of the boreholes, it can be concluded that it is not the dominant control in the studied site. Given that VOC can be dangerous even at trace concentrations; the investigated site is recommended for remediation.

\section{REFERENCES}

AYYUB, B.M. AND R.H. McCUEN. 2011. Probability, statistics and reliability for engineers and scientists (3rd Ed.). CRC Press, Taylor and Francis Group, 6000 Broken Sound Parkway NW, Suit 300, Boca Raton, US.

BOULT, S., P. MORRIS AND S. TALBOT. 2011. Contaminated land application in real environment (CL:AIRE) bulletin, RB 13. [Available online] URL: http://www.ground-gassolutions.co.uk.

CHOI, J-W. AND J.A. SMITH. 2005. Geoenvironmental factors affecting organic vapour advection and diffusion fluxes from the unsaturated zone to the atmosphere under natural conditions. Environ. Eng. Sci., 22 (1): 95-108.

DAVIS, G.B., M.G. TREFRY AND B.M. PATTERSON. 2004. Petroleum and solvent vapours: quantifying their behaviour, assessment and exp-osure. CSIRO land and water report to the Western Australian Department of the Environment, Perth.

ENVIRONMENT AGENCY, 2008. Updated technical background to the CLEA model. Environment Agency Science Report SC050021/SR3.

EPA, 2017. Volatile organic compounds' impact on indoor air quality. Environmental Protection Agency. Retrieved 2017-04-19.

HSE, 2000. Investigation of the explosion at Linfield street Dundee, $22^{\text {nd }}$ of October 2000. A report of the investigation by the health and safety executive of the explosion and fire at 21-25 Linfield Street Dundee on the $22^{\text {nd }}$ of October 2000.

IARC, 2004. International Agency for Research on cancer (IARC), overall evaluation of carcinogennicity to humans, IARC monographs vol. 1-88.

INVITTO, S. AND A. MAZZATENTA. 2019. Olfactory event-related potentials and exhaled organic volatile compounds: the slow link between olfactory perception and breath metabolic response. A pilot study on phenylethyl alcohol and vaseline oil. Brain Sciences, 9 (4): 84.

KATY, B., H. HELEN, P. LARA, B. DON AND M. CECILIA. 2009. The VOCs handbook: Investigation, assessing, and managing risks from inhalation of VOCs at land affected by contamination. CIRIA Report 766, London.

LYNGE, E., A. ANDERSEN, R. NILSSON, L. BARLOW, E. PUKKALA, R. NORDLINDER, P. BOFFETTA, P. GRANDJEAN, P. HEIKKILA, T. RIISE. 1997. Risk of cancer and exposure to gasoline vapours. Am J of Epidemiology, 145, 449-458. 
MARI, M., A. HERMANNI, H. JUSSI, H. HEIDI, P. JUKKA AND B. JAANA. 2019. Boreal forest soil is a significant and diverse source of volatile organic compounds. Plant and Soil, 441, 89-110.

MAXIMILIAN, A. AND K. RYAN. 2009. Cleaning the air? the effects of gasoline content regulation on air quality. Centre for the Study of Energy Markets (CSEM) Working Paper Series, University of California Energy Institute, 2547 Channing Way Berkeley, California, 94720-5180. www.ucei.org.

MAZZATENTA, A., M. POKORSKI AND C. DI GIULIO. 2013. Real-time breath analysis in type 2 diabetes patients during cognitive Effort. Neurobiology of respiration. Advances in Experimental Medicine and Biology, 788, 247-253.

MAZZATENTA, A., M. POKORSKI AND C. DI GIULIO. 2015a. Real time analysis of volatile organic compounds (VOCs) in centenarians. Respiratory Physiology \& Neurobiology, 209, 47-51.

MAZZATENTA, A., M. POKORSKI, D. MONTINARO AND C. DI GIULIO. 2014. Chemoresponsiveness and breath physiology in anosmia neurotransmitter interactions and cognitive function. Advances in Experimental Medicine and Biology, 837, 35-39.

MAZZATENTA, A., M. POKORSKI, F. SARTUCCI, L. DOMENICI, C. DI GIULIO. 2015b. Volatile organic compounds (VOCs) fingerprint of alzheimer's disease. Respiratory Physiology \& Neurobiology, 209, 81-84.

MAZZONE, P.J. 2008. Analysis of volatile organic compounds in the exhaled breath for the diagnosis of lung cancer. J of Thor. Oncology, 3 (7): 774-780.

MENDELL, M. J. 2007. Indoor residential chemical emissions as risk factors for respiratory and allergic effects in children: a review. Indoor Air, 17 (4): 259-77.

MINNESOTA DEPARTMENT OF HEALTH, 2018. Volatile organic compounds (VOCs) in your homeEH.Health.state.mn.us. Retrieved 2018-01-23.

NWACHUKWU, A.N. 2015a.Characterization of volatile organic compounds (VOCs) at an industrial lagoon site in north-west England, UK. International Journal of Current Research and Academic Review, 3 (10): 164-177.

NWACHUKWU, A.N. 2015b. Volatile organic compounds characterization: case study of a tank farm in the United States. JSM Environmental Science and Ecology 3 (2): 1019.

NWACHUKWU, A.N. 2015c. Identification and quantification of volatile organic compounds (VOCs) from a drinking water-well in the United States. Octal J of Environmental Res, 3 (3): 235-243.

NWACHUKWU, A.N. AND D. ANONYE. 2013. The effect of atmospheric pressure on methane (CH4) and carbon dioxide $\left(\mathrm{CO}_{2}\right)$ emission from a closed landfill in Manchester, United Kingdom. Environmental Monitoring and Assessment, 185 (17): 5729-5735.

NWACHUKWU, A.N. AND C.D. HENRY. 2016. Volatile organic compounds (VOCs) at a gasoline retail Site in the United States. International Journal of Scientific Research, 5 (10): 298-302.

NWACHUKWU, A.N. AND C.D. HENRY. 2017. Investigating a southern Manchester landfill leac-hate. Advances in Research, 9 (3): 1-6.

NWACHUKWU, A.N. AND N.V. NWACHUKWU. 2020. Water table: the dominant control on $\mathrm{CH} 4$ and $\mathrm{CO} 2$ emission from a closed landfill site. Advances in Environmental Research, 9 (2):123-133.

NWACHUKWU, A.N., G.U. SIKAKWE AND A. OTELE. 2018. In-Borehole monitoring of greenhouse gas fluxes from upland peat. Middle-East Journal of Scientific Research, 26 (3): 370-377.

NWACHUKWU, A.N. AND C.U. UWA. 2018. The utility of a dual monitoring methodology to determine concentration of specific VOCs at high temporal resolution. Middle-East Journal of Scientific Research, 26 (3): 378-394.

SEEWALD, M.S.A., M. BONFANTI, W. SINGER, B.A. KNAPP, A. HANSEL, I. FRANKE-WHITTLE AND H. INSAM. 2010. Substrate induced VOC emissions from compost amended soils. Biology \& Fertility of Soils, 46, 371-382.

STOTZKY, G. AND S. SCHENCK. 1976. Volatile organic compounds and microorganisms. CRC Crit Rev Microbiol., 4, 333-382

ROWE, B.L., P.L. TOCCALINO, M.J. MORAN, J.S. ZORGOSKI AND C.V. PRICE. 2007. Occurrence and potential human-health relevance of volatile organic compounds in drinking water from domestic wells in the United States. Environmental Health Perspective, 115, 1539-1546.

SERGIO, M.C., A. GRACIELA, R.C.M. MONICA AND M.P.G.O. KATIA. 2012. The impact of BTEX emissions from gas stations into the atmosphere. Atmospheric Pollution Research, 3, 163-169.

SRIVASTAVA, A., A.E. JOSEPH, A. MORE AND S. PATIL. 2005. Emissions of VOCs at urban petrol retail distribution centres in India (Delhi and Mumbai). Environmental Monitoring and Assessment, 109, 227-242.

TILLMAN JR, F.D. AND J. A. SMITH. 2005. Site characteristics controlling airflow in the shallow unsaturated zone in response to atmospheric pressure changes. Environmental Engineering Science, 22, 25-37.

TILLMAN, F.D. AND J.W. WEAVER. 2005. Review of recent research on vapour intrusion. U.S. Environmental Protection Agency-Office of Research and Development, Washington DC, 20460.

USEPA, OAR, 2014.Technical overview of volatile organic compounds. United State Environmental Protection Agency. Retrieved 2019-04-04.

WILSON, S., S. OLIVER, H. MALLET, H. HUTCHINGS AND G. CARD. 2007. Assessing risks posed by hazardous ground-gases to buildings. CIRIA C665, London, 182p.

WOLKOFF, P., C.K. WILKINS, P.A. CLAUSEN AND G.D. NIELSEN. 2006. Organic compounds in office environments-sensory irritation, odor, measurements and the role of reactive chemistry. Indoor Air, 16 (1):7-19. 